\title{
Tavoitteena turvallisuus
}

\author{
Miten kehittää turvallisuus- \\ kulttuuria ja tukea kriiseistä \\ oppimista sairaaloissa?
}

\begin{abstract}
$+y$
Turvallisuuden varmistaminen on keskeinen osa sairaaloiden toimintaa. Yliopistollisissa sairaaloissa tehty haastattelututkimus osoittaa, että turvallisuuskulttuurin kehittämisessä tarvitaan jaettua ymmärrystä, yhteistyötä ja johtamista. Kriiseistä oppimista edistävät koulutus, avoimuus, tarkoituksenmukaiset viestintäkanavat sekä tiedon ja kokemusten jakaminen.
\end{abstract}

$\mathbf{y}$ NOPEASTI MUUTTUVASSA, yhä monimutkaisemmassa maailmassa turvallisuus kiinnostaa niin kansainvälisellä, kansallisella ja alueellisella kuin ryhmä- ja yksilötasolla. Turvallisuus voidaan määritellä uhkien ja riskien puuttumisena, kykynä vastata niihin, toimintana niiden hallitsemiseksi tai psykologisesti koettuna tunteena, että uhkat ja riskit ovat hallittavissa (Eskola 2008, 1; Kokonaisturvallisuuden sanasto 2017, 16). Keskiöön nousee kysymys, ketä tai mitä turvataan, keneltä tai miltä ja miten (Eskola 2008, 1).

Turvallisuuden vaatimukset ulottuvat kaikkien organisaatioiden toimintaan. Organisaatiot joutuvat arjessaan kehittämään turvallisuutta esimerkiksi työja tietoturvallisuuden näkökulmasta. Turvallisuuden luomisessa, ylläpitämisessä ja kehittämisessä tarvi- taan viestintää niin organisaation sisäisten kuin ulkoisten sidosryhmien kesken. Tutkimusten mukaan onnistunut viestintä ja toimiva tiimityö edistävät turvallisuutta muun muassa sairaaloissa (Gluyas 2015, 50; Leonard, Graham \& Bonacum 2004) ja rakennusalalla (Pandit ym. 2019, 2). Lisäksi viestintä edistää oppimista organisaatioissa (Collin 2002, 141; Laajalahti 2014, 72; Marsick \& Watkins 2003, 139), mikä on tärkeää, sillä turvallisuus edellyttää organisaatioilta ja työntekijöiltä jatkuvaa oppimista ja toiminnan kehittämistä.

Tutkimukset ovat keskittyneet organisaatioiden ulkoiseen kriisiviestintään ja maineenhallintaan, kriisiviestintästrategioihin sekä sidosryhmien ja median reaktioihin. Kriisiviestintää on tarkasteltu vähemmän organisaatioiden sisäisen toiminnan 
kannalta (Frandsen \& Johansen 2011, 347; Heide \& Simonsson 2015, 224; Mazzei \& Ravazzani 2015, 320). Tämän tutkimuksen tavoite on lisätä ymmärrystä turvallisuuskulttuurin rakentamisesta ja kriiseistä oppimisen tukemisesta sairaaloissa. Lähestymme aihettamme erityisesti sairaaloiden sisäisen kriisiviestinnän näkökulmasta. Tutkimuskysymykset ovat seuraavat:

1) Miten turvallisuuskulttuuria voidaan kehittää sairaaloissa?

2) Miten kriiseistä oppimista voidaan tukea sairaaloissa?

Tarkastelemme tutkimusaihetta laadullisen tutkimuksen keinoin. Tutkimusaineisto koostuu kaikkien viiden Suomen yliopistollisen sairaalan turvallisuusja viestintäpäälliköiden haastatteluista $(\mathrm{N}=10)$, ja lähestymme aihetta tutkittavien itsensä kokemana ja kuvaamana. Sairaalat ovat otollinen tutkimuskohde, koska turvallisuus on niissä kirjaimellisesti elämän ja kuoleman kysymys. Rajasimme tutkimuksemme yliopistollisiin sairaaloihin, sillä niiden toiminta on muita sairaaloita laajempaa ja erikoistuneempaa (Sosiaali- ja terveysministeriö 2019). Tutkimuksen avainkäsitteitä ovat kriisiviestintä, turvallisuuskulttuuri ja kriiseistä oppiminen sairaaloissa. Niitä kaikkia on jo tutkittu, mutta niiden yhdistäminen samaan tutkimukseen on harvinaista.

Tutkimuksen lähtökohtana on kolme ajatusta: Ensinnäkin sairaaloiden sisäisellä kriisiviestinnällä voidaan kehittää turvallisuuskulttuuria ja tukea kriiseistä oppimista. Toiseksi turvallisuuskulttuuri vaikuttaa kriisiviestintään ja kriiseistä oppimiseen. Kolmanneksi kriiseistä oppiminen tukee kriisiviestinnän ja turvallisuuskulttuurin kehittymistä.

\section{KRIISIT JA KRIISIVIESTINTÄ SAIRAALOISSA}

Kriisi on odottamaton, uhkaava tilanne tai tapahtumien sarja, jota luonnehtivat yllätyksellisyys, ennakoimattomuus, epätietoisuus ja lyhyt reagointiaika (Ulmer, Sellnow \& Seeger 2015). Se asettaa organisaatiolle totutusta poikkeavia vaatimuksia, aiheuttaa epävarmuutta ja uhkaa sidosryhmien odotuksia
(Adkins 2010). Akuutti kriisitilanne, esimerkiksi räjähdys, voi olla lyhytkestoinen, mutta kriisi voi myös kestää useita kuukausia, kuten covid-19-pandemia, ja synnyttää uusia kriisejä. Esimerkiksi luonnonkatastrofi voi aiheuttaa talouskriisin.

Sairaalat ovat jatkuvassa pienten ja suurten kriisien tilassa: odottamaton on odotettua (Heide \& Simonsson 2014, 134). Niiden turvallisuutta voivat uhata monenlaiset kriisit ja niin tahallinen kuin tahaton vahingollinen toiminta: kriisejä voivat olla esimerkiksi hoitovirhe, tietoliikennekatkos, kyberhyökkäys, tulipalo, sähkökatkos, väkivaltatilanne tai lähistöllä tapahtunut suuronnettomuus, joka ruuhkauttaa sairaalan.

Koska kriisit luovat epävarmuutta, ne luovat tiedontarpeita (Seeger, Sellnow \& Ulmer 2003) ja edellyttävät kriisiviestintää eli vuorovaikutusta, jossa tapahtumia ja niiden syitä ja seurauksia pyritään yhdessä ymmärtämään (Vos 2017). Kriisiviestinnällä tarkoitetaan kaikkea kriisiin vastaamiseen tarvittavaa tiedon keräämistä, prosessointia ja vaihdantaa (Coombs 2007).Viestinnällä voidaan muun muassa valmistautua kriiseihin ja minimoida niiden seurauksia (Adkins 2010, 98).

Kriisiviestintää lähestytään usein yksisuuntaisena, ylhäältä alas ja organisaatioiden sisältä ulos suuntautuvana toimintana (Falkheimer \& Heide 2010; Frandsen \& Johansen 2011). Se on kuitenkin monimuotoista vuorovaikutusta: kaikkea sitä ihmisten välistä kanssakäymistä, jota tarvitaan kriiseihin varautumisessa, niistä selviämisessä sekä oppimisessa niin organisaation sisäisten kuin ulkoisten sidosryhmien kesken (Laajalahti 2016). Kriisiviestintä linkittyy läheisesti riskiviestintään. Havaitsemattomista tai käsittelemättömistä riskeistä voi kehittyä kriisejä, joten riskeistä viestiminen on osa kriiseihin varautumista ja toisinaan niiden jälkihoitoa (Coombs 2010, 54-58).

Organisaatioiden sisäinen kriisiviestintä keskittyy tiedontarpeisiin ja kriisien merkityksentämiseen työntekijöiden ja johtajien kesken (Heide \& Simonsson 2014, 129). Se on vähemmän tutkittu alue kuin ulkoinen kriisiviestintä (Coombs 2010, 46; Frandsen \& Johansen 2011, 347; Heide \& Simonsson 2014, 131; 2015, 224; Mazzei \& Ravazzani 2015, 320), mutta vähintäänkin yhtä tärkeä. Työntekijät tulkitsevat kriisejä 
OrganisaATIOKULTTUURI

LUO POHJAN ORGANISAATION

TURVALLISUUS-

KULTTUURILLE.

eri tavoin ammatistaan, asemastaan, tietämyksestään ja verkostoistaan riippuen, ja kriisien yhdessä ymmärrettäväksi tekeminen on organisaatiolle tärkeää (Mazzei \& Ravazzani 2011).

Kriiseistä erotetaan usein kolme vaihetta: aika ennen kriisiä, kriisin aikana ja kriisin jälkeen (Veil 2011; Vos 2017). Kriisit eivät kuitenkaan aina etene lineaarisesti (Chess 2001) eikä niille voi aina määrittää alku- tai loppupistettä (Boano \& Lund 2011). Niitä onkin usein mielekkäämpää tarkastella prosesseina (Reynolds \& Seeger 2005). Tässä tutkimuksessa lähestymme myös kriisiviestintää prosessina ja viittaamme 'sisäisellä kriisiviestinnällä' kaikkeen kriiseihin liittyvään viestintään ja vuorovaikutukseen sairaaloissa ennen kriisejä, niiden aikana ja jälkeen.

\section{TURVALLISUUSKULTTUURI SAIRAALOIDEN TURVALLISUUDEN PERUSTANA}

Sairaalat ovat turvallisuuskriittisiä, korkean riskin organisaatioita. Tällaisissa organisaatioissa toiminnan luotettavuuden varmistaminen on erityisen tärkeää ja samalla vaikeaa, virheillä voi olla vakavia seurauksia ja toimintaan liittyy vaaroja sekä uhkia, jotka voivat aiheuttaa kohtalokasta vahinkoa (Kinnunen 2010; Reiman \& Oedewald 2008). Turvallisuuden vaatimukset koskevat sairaaloissa muun muassa työ-, potilas-, lääke-, tieto-, kyber-, kiinteistö-, palo- ja pelastusturvallisuutta. Monet Suomen lait, kuten laki potilaan asemasta ja oikeuksista (Oikeusministeriö 1992/785), erikoissairaanhoitolaki (Oikeusministeriö 1989/1062) ja tietosuojalaki (Oikeusministeriö 2018/1050) ohjaavat sairaaloiden toimintaa ja velvoittavat niitä hoitamaan turvallisuusasiansa.

Turvallisuuden varmistaminen ja vaikuttava kriisien hallinta on mahdollista vain, kun kyvystä kohdata kriisejä tulee osa sairaaloiden organisaatiokult- tuuria (Schermuly ym. 2015, 1). Organisaatiokulttuurilla tarkoitetaan organisaation jäsenten jakamia arvoja, merkityksiä, uskomuksia, oletuksia ja odotuksia. Se vaikuttaa siihen, miten organisaation jäsenet ajattelevat, toimivat, tuntevat ja tulkitsevat asioita. Se muuttuu hitaasti mutta jatkuvasti vuorovaikutuksessa. Samaan aikaan kun organisaatiokulttuuri vaikuttaa viestintään organisaatiossa, viestinnällä on mahdollista vaikuttaa organisaatiokulttuuriin. (Ks. esim. Keyton 2011; Schein 1984.)

Organisaatiokulttuuri on yhteydessä organisaation turvallisuuteen ja siihen, miten organisaatiossa nähdään ja muistetaan kriisit. Se vaikuttaa muun muassa siihen, miten organisaatiossa selitetään koettuja kriisejä, miten havaittuihin epäkohtiin suhtaudutaan ja millainen psykologinen kriisivalmius organisaatiossa on (Frandsen \& Johansen 2011, 355). Organisaatiokulttuuri luo siis pohjan organisaation turvallisuuskulttuurille, ja turvallisuuskulttuuri on osa organisaatiokulttuuria (Lee ym. 2019, 299; Morello ym. 2013, 2).

Turvallisuuskulttuuri on organisaation kykyä ja tahtoa ymmärtää, millaista turvallinen toiminta on, millaisia vaaroja organisaation toimintaan liittyy, miten vaaroja voidaan ehkäistä ja miksi turvallisuus on tärkeää (Reiman \& Oedewald 2008). Turvallisuuskulttuuri muuttuu koko ajan, ja sen kehittäminen on kaikkien työntekijöiden vastuulla (Kinnunen 2010). Turvallisuuskulttuuri ja sisäinen kriisiviestintä ovat tiiviisti yhteydessä toisiinsa, sillä viestinnällä ylläpidetään yhteistä tietoisuutta turvallisuudesta (Frandsen \& Johansen 2011; Leonard, Graham \& Bonacum 2004; Strandberg \& Vigsø 2016). Turvallisuutta voidaan parantaa siis kehittämällä turvallisuuskulttuuria ja sisäistä kriisiviestintää; prosessi alkaa jo kauan ennen kuin varsinainen turvallisuutta uhkaava kriisi syntyy.

\section{KRIISEISTÄ OPPIMINEN SAIRAALOISSA}

Onnistunut kriisiviestintä ja turvallisuuskulttuurin kehittäminen edellyttävät organisaatioilta oppimista. Organisaatioiden oppimista kriiseissä on kuitenkin tutkittu vain vähän (Larsson 2010, 713). Kriisit määritellään usein seurauksiltaan negatiivisiksi ta- 
pahtumiksi (Coombs 2007), mutta ne voivat auttaa organisaatioita oppimaan ja kehittymään (Ulmer, Sellnow \& Seeger 2015; Veil 2011). Kriisit tarjoavat muun muassa mahdollisuuden toimivien käytänteiden levittämiseen sekä esille tulleiden puutteiden korjaamiseen (Larsson 2010).

Kaikki organisaatiot oppivat, mutta kaikki eivät tee sitä tehokkaasti (Marsick \& Watkins 2003). Organisaatiokulttuuri ja johtaminen vaikuttavat siihen, miten organisaatiossa opitaan (Coombs 2007, 26; Kinnunen 2010, 4; Larsson 2010, 714). Oppimisen tukeminen edellyttääkin kokonaisvaltaista kulttuurin muutosta (Kofman \& Senge 1993; Veil 2011). Oppimista edistävässä organisaatiokulttuurissa sallitaan virheiden tekeminen ja kannustetaan epäkohtien esille tuomiseen (Kinnunen 2010). Syyllisten etsimisen sijaan keskitytään kriisien tarjoamiin mahdollisuuksiin oppia (Ulmer, Sellnow \& Seeger 2015) ja seuraavan kriisin reaktiivisen odottelun sijaan proaktiiviseen toiminnan kehittämiseen (Kofman \& Senge 1993). Tämänkaltainen oppimismyönteinen organisaatiokulttuuri on äärimmäisen tärkeää kriiseihin varautumisessa (Wang, Hutchins \& Garavan 2009, 42).

Oppiminen on kollektiivinen kokemus ja edellyttää vuorovaikutusta (Marsick \& Watkins 2003). Oppivassa organisaatiossa työntekijöitä kannustetaan yhteistyöhön ja avoimeen vuorovaikutukseen, kyseenalaistamiseen, palautteen antamiseen, kokeiluihin ja kokemuksien jakamiseen (Kinnunen 2010, 143-144; Marsick \& Watkins 2003, 139). Viestintä ja vuorovaikutus voivatkin parhaimmillaan edistää ja pahimmillaan ehkäistä oppimista (Laajalahti 2014, 72).

\section{TUTKIMUKSEN TOTEUTUS}

Lähestymme turvallisuuskulttuurin kehittämistä ja kriiseistä oppimisen tukemista erityisesti sairaaloiden sisäisen kriisiviestinnän näkökulmasta. Tarkastelemme tutkimusaihetta laadullisen tutkimuksen keinoin, tutkittavien itsensä kokemana ja kuvaamana. Keräsimme tutkimusaineiston kaikista viidestä Suomen yliopistollisesta sairaalasta haastattelemalla turvallisuus- ja viestintäasioista vastaavia henki- löitä. Haastattelimme kustakin sairaalasta kahta henkilöä, joten vastaajia oli yhteensä kymmenen: viisi työskenteli turvallisuuspäällikkönä, neljä viestintäpäällikkönä ja yksi viestinnästä vastaavana kehitysjohtajana.

Toteutimme haastattelut teemahaastatteluina: keskustelimme kaikkien kanssa etukäteen päätetyistä teemoista, mutta teemojen käsittelyjärjestys ja kysymysten tarkka muoto vaihtelivat (Hirsjärvi \& Hurme 2008; Ruusuvuori, Nikander \& Hyvärinen 2010). Kaikissa haastatteluissa painottuivat samat teemat: 1) kriiseihin varautuminen ja ennaltaehkäisy, 2) turvallisuuskulttuurin kehittäminen ja 3) kriiseistä oppiminen. Lisäksi kysyimme haastattelujen alussa taustatietoja orientaationa aiheeseen. Huomioimme kysymysten asettelussa vastaajien erikoisosaamisen ja ammattitaidon: turvallisuuspäälliköiden haastatteluissa painottuivat turvallisuuden nykytila ja kehittämiskohteet ja viestintäpäälliköiden haastatteluissa kriisiviestinnän nykytila ja kehittämiskohteet. Kysymyksiä oli yhteensä nelisenkymmentä, ja haastattelut kestivät keskimäärin tunnin.

Lähestyimme haastateltavia henkilökohtaisesti sähköpostilla tai puhelimella. Kaikki mukaan pyydetyt henkilöt suostuivat haastatteluun. Teimme ja nauhoitimme haastattelut kasvokkain. Aineistonkeruun jälkeen litteroimme haastattelut mahdollisimman tarkasti; aineistoa kertyi 122 sivua (54297 sanaa). Anonymisoimme tutkimusaineiston, ja annoimme kaikille haastatelluille oman lyhenteen (turvallisuuspäälliköt: T1-T5, viestintäpäälliköt: V1-V5).

Analysoimme tutkimusaineiston laadullisesti, sillä olimme tutkimuksessa kiinnostuneita haastatteluissa kuvattavista ilmiöistä ja merkityksistä, emme esimerkiksi asioiden yleisyydestä. Aloitimme analyysin lukemalla litteroidun aineiston huolellisesti läpi. Sitten teemoittelimme aineiston (Hirsjärvi \& Hurme 2008; Schwandt 2007) tutkimuskysymyksittäin ja pyrimme löytämään keskeisimmät näkökulmat kumpaankin pääteemaan: turvallisuuskulttuurin kehittämiseen ja kriiseistä oppimisen tukemiseen. Rajasimme analyysin ulkopuolelle kaiken sen aineiston, joka ei liittynyt tutkimuskysymyksiin.

Tämän jälkeen tarkastelimme kumpaakin pääteemaa yksityiskohtaisesti omana kokonaisuutenaan, 
TURVALLisUUSASIAT ON

T $\ddot{A} R K E \ddot{A A}$ TUODA ESIIN OSANA

VASTUULLISTA TYÖNTEKOA

JA TYÖST $\ddot{A} \ddot{A}$ YLPEÄN

\section{AMMATTILAISEN TOIMINTAA.}

ja syvensimme analyysia etsimällä ja muodostamalla kumpaakin pääteemaa tarkentavia alateemoja. Löysimme kaikkien pääteemojen alta alateemoja eli asioita, jotka toistuivat useassa haastattelussa: esimerkiksi jaetun ymmärryksen synnyttäminen turvallisuudesta, turvallisuusnäkökulmien huomioiminen kaikessa tekemisessä. Alateemoihin syventymällä löysimme vastaukset tutkimuskysymyksiin.

Teemoittelun jälkeen etsimme aineistosta vielä erikseen turvallisuuskulttuurin kehittämiseen liittyviä sairaaloiden turvallisuuskulttuuria haastavia jännitteitä. Jännitteiden hahmottamisessa hyödynsimme Leslie Baxterin ja Barbara Montgomeryn (1996) relationaalisen dialektiikan viitekehystä. Se on sateenvarjokäsite erilaisille tavoille tarkastella vuorovaikutuksessa esiintyviä jännitteitä ja ristiriitaisuuksia: vastakkaisia voimia, joiden samanaikainen läsnäolo tekee vuorovaikutuksesta alati muuttuvaa. Hyödynsimme viitekehystä turvallisuuskulttuurin kehittämisen jännitteisen luonteen hahmottamisessa, mutta analysoimme aineiston aineistolähtöisesti ja muodostimme kunkin jänniteparin aineistosta käsin.

\section{TURVALLISUUSKULTTUURIN KEHITTÄMINEN SAIRAALOISSA}

Haastateltavien mukaan turvallisuuskulttuuria voidaan kehittää sairaaloissa 1) jaettua ymmärrystä turvallisuudesta synnyttämällä, 2) turvallisuusnäkökulmat kaikessa tekemisessä huomioimalla, 3) ohjeistuksia kehittämällä, 4) yhteistyötä tukemalla ja pirstaloitumista ehkäisemällä, 5) työntekijöitä osallistamalla sekä 6) johtamista kehittämällä.

Turvallisuuskulttuuria pidettiin yleisesti monen kulttuurin yhdistelmänä ja sen todettiin vaihtelevan yksiköstä toiseen. Esimerkiksi leikkaustoiminnassa korostuu potilasturvallisuus ja psykiatrian yksikössä työntekijöiden turvallisuus. Haastateltavien mukaan turvallisuuskulttuuria voidaan kehittää synnyttämällä jaettua ymmärrystä turvallisuudesta. Se voi syntyä, kun asioista keskustellaan yhdessä ja turvallisuuteen luodaan ymmärrettävät ohjeistukset sekä selkeät periaatteet. Asioiden listaaminen paperille ei kuitenkaan riitä, vaan turvallisuus on tuotava osaksi jokapäiväisiä käytänteitä ja prosesseja. Sitä on pidettävä työssä ja keskusteluissa jatkuvasti esillä.

Käytännössä esillä pitäminen edellyttää turvallisuuden nivomista osaksi arkista ajattelua ja toimintaa. Turvallisuuden tulee olla tausta-ajatuksena kaikessa, mitä sairaaloissa tehdään. Kun turvallisuusnäkökulmat otetaan huomioon kaikessa tekemisessä, rakennetaan turvallisuuskulttuuria, jossa kaikki organisaation työntekijät ymmärtävät jokapäiväisen toimintansa merkityksen sekä roolinsa ja vastuunsa turvallisuuden kokonaisuudessa. Tämä edellyttää heiltä turvallisuusasioiden huomiointia, totuttujen ajattelu- ja toimintatapojen sekä olemassa olevien käytänteiden kyseenalaistamista ja poikkeamista raportointia. Turvallisuusasiat on tärkeää tuoda esiin osana vastuullista työntekoa ja työstään ylpeän ammattilaisen toimintaa.

Suuren organisaation haasteena on turvallisuuden kokonaiskuvan luominen ja turvallisuuden ymmärtäminen riittävän laajasti: esimerkiksi sairaalassa turvallisuus rinnastetaan helposti potilasturvallisuuteen. Työntekijöiden pitää kuitenkin huomioida myös esimerkiksi oven eteen jätetyn potilassängyn luoma paloturvallisuusriski ja auki jätetyn tietokoneen tietoturvariski. Toinen haaste on vastuun ottaminen: turvallisuus kuuluu kaikille, mutta se mielletään helposti vain tiettyjen henkilöiden vastuualueeksi.

"Silloin kun sitä ei tartte ajatella, niin silloin se on hyvä asia. Kyllä ne ajattelee, ymmärtääkseni kyllä, erityisesti potilaan hoidon turvallisuutta ja sitä kautta omaa turvallisuuttaan kanssa. Ei aktiivisesti tarviikaan ajatella, mut jos jotain tapahtuu, niin pystytään toimimaan ja jos nähdään epäkohtia, niin niihin puututaan." (T4)

Sairaalat ovat suuria organisaatioita, jotka panostavat suunnitteluun. Riskejä kartoitetaan ja erilaisia turvallisuuden osa-alueita ohjeistetaan laajasti. Haas- 
tattelujen perusteella turvallisuuskulttuuria voidaan parantaa ohjeistuksia kehittämällä. Parhaimmillaan ohjeistukset ovat helposti omaksuttavia ja toisiaan tukevia, huonoimmillaan kirjava joukko eri asioita painottavia dokumentteja.

Ohjeistusten määrästä voi seurata dokumenttien kaaos. Tietoa on periaatteessa tarjolla, mutta sen löytäminen ja omassa työssä olennaisten seikkojen erottaminen on vaikeaa. Ohjeistukset ovat usein pitkiä ja raskaita, eikä niiden sisältö avaudu ilman havainnollistamista. Lisäksi ohjeistukset vanhenevat, ja niiden ylläpito voi unohtua. Huomionarvoista on, että ohjeet keskittyvät usein toimintaan kriisitilanteessa, ja ennaltaehkäisy ja kriiseistä oppiminen jäävät niissä vähemmälle. Turvallisuuskulttuurin kehittämisessä onkin tärkeää miettiä konkreettisesti, miten työntekijät löytävät helposti juuri sen tiedon, mitä turvallisuus heidän työssään vaatii.

Haastattelujen perusteella turvallisuuskulttuuria voidaan kehittää yhteistyötä tukemalla ja pirstaloitumista ehkäisemällä. Sairaaloissa turvallisuuden haastaa tiedon ja työtehtävien pirstaleisuus. Turvallisuuden osa-alueiden hallinnan ja niistä vastaavien henkilöiden yhteistyön on oltava tiivistä. Esimerkiksi säännölliset tapaamiset turvallisuuden eri osa-alueista vastaavien avainhenkilöiden kesken voivat lisätä jaettua ymmärrystä turvallisuudesta ja tuoda esiin yhteisiä kehittämiskohteita ja tavoitteita. Samalla voidaan varmistaa eri tahojen laatimien ohjeistuksien ja toimintatapojen yhdenmukaisuus. Muuten vaarana on, että jokainen näkee vain oman kapean vastuualueensa, ja kokonaiskuva sekä oman toiminnan vaikutus kokonaisturvallisuuteen jäävät hämäriksi.

Haastattelujen perusteella yhteistyössä turvallisuudesta ja viestinnästä vastaavien avainhenkilöiden kesken on vielä kehittämisen varaa. Yhteistyön kehittäminen ja tiedon ja työtehtävien pirstaloitumisen ehkäiseminen vaativat tapaamisia, tiedonvaihtoa ja vuoropuhelua.

"Meillä on osaavia ihmisiä, meillä on päteviä ihmisiä, meillä on niin kun mahdollisuuksia tehdä asioita, mut tällä hetkellä on vähän niin, että meillä on paljon viulisteja, mut ne ei soita samassa bändissä, vaan ne soittaa vähän samaa biisiä eri kadunnurkis- sa, vähän eri sävellajista, mut kun ne saatas saman partituurin eteen, niin se soittais aika hyvin." (T2)

Turvallisuuskulttuuria kehitetään työntekijöitä osallistamalla: heidät pitää saada ymmärtämään turvallisuuden merkitys ja oman panoksen tärkeys. Ei riitä, että turvallisuutta pidetään yleisesti arvokkaana asiana, vaan työntekijöiden on osattava ajatella kriittisesti omaa työtään ja motivoiduttava turvallisuuden kehittämiseen. Työntekijöiden osallistamista tukee kehitys- ja keskustelumyönteinen organisaatiokulttuuri, jossa epäkohtia uskalletaan nostaa esiin. Osallistumisella on lisäksi oltava vaikutusta: työntekijöiden on koettava, että he voivat vaikuttaa turvallisuuskulttuurin kehittämiseen.

Haastateltavien mukaan turvallisuuskulttuuria voidaan parantaa myös johtamista kehittämällä. Jos johtajat eivät sitoudu turvallisuuskulttuurin kehittämiseen, sitä ei voida odottaa työntekijöiltäkään. Turvallisuusasioiden arvostuksen pitää näkyä strategioissa ja suunnitelmissa, mutta ennen kaikkea käytännön toiminnassa ja johtajien painotuksissa. Johtajien on varmistettava, että työntekijöillä on riittävät edellytykset ja resurssit huolehtia turvallisuudesta. Lisäksi johtajien tulee aktiivisesti viestiä jokaisen työntekijän vastuista ja velvoitteista sekä turvallisuuteen vaikuttamisen mahdollisuuksista. Tärkeää on esimerkillä johtaminen: johtajien suhtautuminen turvallisuuteen heijastuu koko organisaatiossa vallitsevaan turvallisuuskulttuuriin.

Myös aiempien tutkimusten mukaan turvallisuuskulttuurin ydinkriteereihin kuuluvat seuraavat seikat: turvallisuus nähdään tärkeänä, ja kaikki kantavat siitä vastuuta; turvallisuutta edistetään jokapäiväisessä toiminnassa; vaarat ja riskit tunnistetaan ja työn hallintaan on riittävät ajalliset, välineelliset ja osaamista koskevat resurssit (Pietikäinen ym. 2010). Turvallisuuskulttuurin kehittämisessä on tarpeen tukea työntekoa suunnittelulla ja ohjeilla, varmistaa riittävät resurssit, kehittää tiedon jakamista ja vahvistaa yhteistyötä. Turvallisuutta uhkaavia ongelmia ja epäkohtia on uskallettava tuoda esille. Etenkin johtajien viestinnän ja turvallisuuskulttuurin kehittämiseen sitoutumisen merkitystä on korostettu aiemminkin. (Morello ym. 2013; Pietikäinen ym. 2010; Stavrianopoulos 2012.) 


\section{TURVALLISUUSKULTTUURIA HAASTAVAT JÄNNITTEET}

Haastateltavien mukaan turvallisuuskulttuurin kehittämiseen liittyy osittain ristiriitaisia vaatimuksia. Olennaista on löytää tasapaino seuraavien jännitteiden välillä: 1) rutiinit-joustavuus, 2) korjaaminen-ennakointi, 3) hierarkia-vastuunjako, 4) suunnitelmatkäytäntö ja 5) sulkeutuneisuus-avoimuus (kuvio 1).

1) Rutiinit-joustavuus. Ilman rutiineja ja sääntöjä sairaaloiden arjen pyörittäminen on mahdotonta, mutta ennalta päätettyjen ohjeistuksien ja toimintamallien mukaan ei voida toimia kaikissa tilanteissa. Turvallisuuskulttuurin kannalta haasteena onkin yhtälätä luoda rutiineja ja selkeitä ohjeistuksia, toisaalta joustaa ja ylläpitää kulttuuria, jossa työntekijät osaavat ja uskaltavat kyseenalaistaa vallitsevia käytänteitä ja ideoida uusia.

2) Korjaaminen-ennakointi. Turvallisuuden varmistaminen vaatii sairaaloissa järjestelmällisyyttä ja toiminnan korjaamista jo koettujen kriisien perusteella. Toisaalta toiminnan reaktiivisen korjaamisen sijaan huomiota on kiinnitettävä proaktiivisesti turvallisuutta uhkaavien kriisien ennakointiin ja ennaltaehkäisyyn.

3) Hierarkia-vastuunjako. Turvallisuus edellyttää sairaaloissa selkeitä vastuualueita ja vahvaa johta- mista, mutta liiallinen hierarkia tukahduttaa turvallisuuskulttuurin kehittämistä ja ylläpitää vanhoja, kankeita käytänteitä. Selkeiden vastuualueiden ja hierarkian ohella turvallisuus edellyttää vastuunjakoa, työntekijöihin luottamista sekä turvallisuuden nostamista kaikkien yhteiseksi asiaksi.

4) Suunnitelmat-käytäntö. Sairaaloiden turvallisuus vaatii suunnitelmia ja ohjeistuksia. Turvallisuuden tekevät kuitenkin viime kädessä ihmiset. Turvallisuuskulttuurin luomisessa on löydettävä toiminnan taustalla olevien suunnitelmien ja käytännön toiminnan kehittämisen välinen tasapaino.

5) Sulkeutuneisuus-avoimuus. Samaan aikaan kun sairaaloissa käsitellään runsaasti salassa pidettäviä tietoja, avoimuus on turvallisuuskulttuurin kehittämisen kannalta keskeistä. Sairaaloiden turvallisuusohjeistukset ovat periaatteessa kaikkien työntekijöiden saatavilla, mutta ne ovat usein vaikeasti löydettävissä. Siksi niistä pitää viestiä aktiivisesti, ja työntekijät pitää osallistaa turvallisuuskeskusteluun. Turvallisuuskulttuurin kehittämiseksi sekä onnistumisia että epäonnistumisia on nostettava avoimesti keskusteluun ketään syyllistämättä.

Turvallisuuskulttuurin ristiriitaisuuksia kuvaavat jänniteparit auttavat ymmärtämään, millaisia haasteita sairaaloiden turvallisuuskulttuurin kehittämiseen sisältyy. Keskeistä on se, että jännitteet tunnistetaan ja

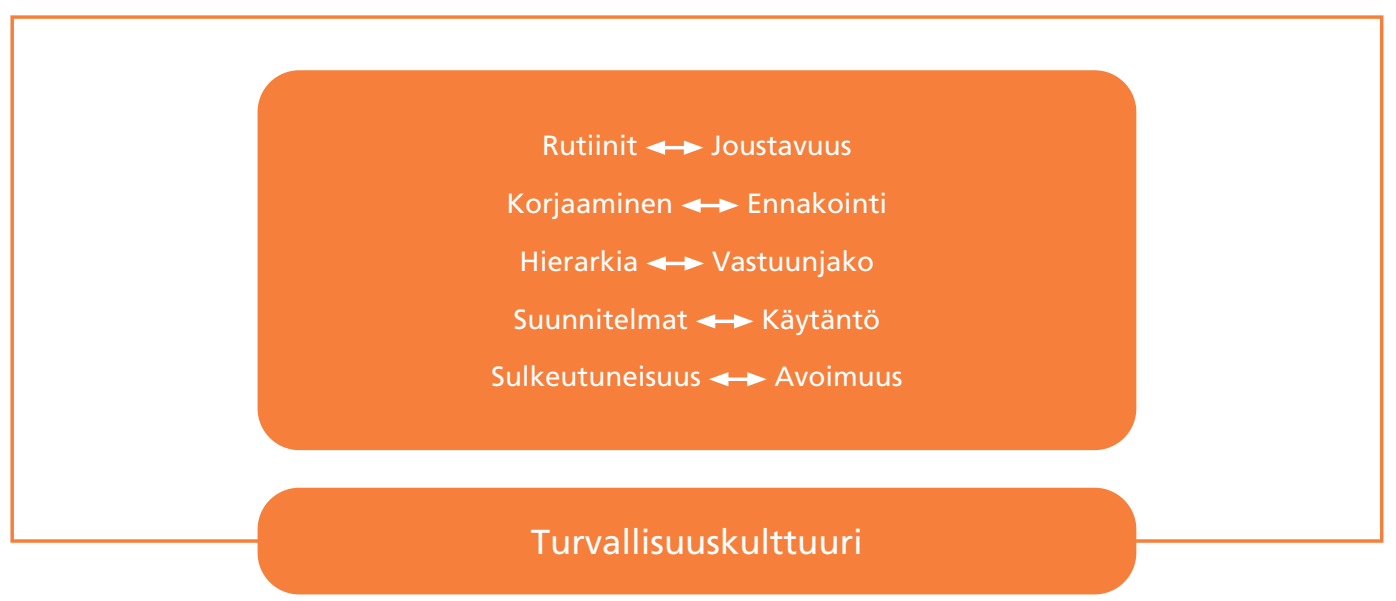

Kuvio 1. Sairaaloiden turvallisuuskulttuuria haastavat jännitteet. 
OlenNaista ON

\section{TASAPAINOTELLA}

\section{ONNISTUNEESTI}

\section{J ̈̈NNITTEIDEN V ̈̈LILL $\ddot{A}$.}

että niistä puhutaan yhdessä työntekijöiden ja johtajien kesken. Keskusteluissa voidaan pohtia yhdessä esimerkiksi sitä, miten jännitteisiin asemoidutaan ja asennoidutaan sekä minkä jänniteparin suhteen turvallisuuskulttuuria halutaan seuraavaksi kehittää ja miten (Heide \& Simonsson 2015).

Keskusteluissa on hyvä muistaa, että jännitteitä ei ole kuitenkaan mahdollista "korjata" tai "poistaa", vaan olennaista on tasapainoilla onnistuneesti niiden välillä (Baxter \& Montgomery 1996). Kumpikaan jänniteparin ääripää ei ole toistaan parempi: kumpaakin tarvitaan ja kumpikin on huomioitava turvallisuuskulttuurin sekä sairaaloiden sisäisen kriisiviestinnän kehittämisessä (Heide \& Simonsson 2015, 249). Jännitteet ovat läsnä jatkuvasti, ne on otettava huomioon ja niiden välillä on tasapainoteltava.

\section{KRIISEISTÄ OPPIMINEN SAIRAALOISSA}

Haastattelujen perusteella kriiseihin varautuminen nojaa sairaaloissa pitkälti totuttuihin käytäntöihin, suunnitelmiin ja harjoitteluun. Sairaaloiden valmius kohdata kriisejä on hyvä, mutta kriisien ennaltaehkäisyyn ja kriiseistä oppimiseen voitaisiin panostaa nykyistä enemmän. Kriiseistä oppimista voidaan tukea sairaaloissa 1) tarjoamalla koulutusta, 2) lisäämällä avoimuutta, 3) varmistamalla tarkoituksenmukaiset viestintäkanavat sekä 4) jakamalla tietoa ja kokemuksia.

Sairaalat voivat tukea kriiseistä oppimista tarjoamalla koulutusta. Kriisien varalle voidaan tehdä ohjeistuksia, mutta niitä ei välttämättä osata noudattaa tositilanteessa ilman käytännön harjoittelua. Turvallisuusohjeistuksia suunniteltaessa ei aina osata huomioida kaikkea, mikä paljastuu harjoittelun kautta. Harjoittelun avulla ohjeistuksia voidaan parantaa, ja organisaation kyky ehkäistä kriisejä sekä kehittää turvallisuuttaan paranee. Lisäksi kriisiosaamista voidaan tukea luentomuotoisilla koulutuksilla. Suurin kynnys on ajankäyttö: harjoittelu ja koulutukset koetaan tärkeiksi, mutta niihin on vaikea löytää aikaa.

Kriiseistä oppimista voidaan tukea avoimuutta lisäämällä eli kiinnittämällä huomiota esimerkiksi siihen, miten organisaatiossa on mahdollista kertoa havaituista epäkohdista ja miten niihin puututaan. Keskustelu pitää mahdollistaa matalalla kynnyksellä ja myös kasvokkain. Työntekijöitä on tärkeä ohjeistaa, miten ja minne havainnoista voi ilmoittaa, ja heitä on tärkeä rohkaista tekemään niin. Syyllistämisen sijaan asioita pitäisi tarkastella kehittämisnäkökulmasta ja keskittyä tilanteen korjaamiseen. Kriisitilanteeseen johtaneet syyt ja seuraukset on jälkikäteen analysoitava yhdessä avoimesti, että tapahtuneesta voidaan oppia ja tarvittaessa poisoppia toimimattomista ajattelu- ja toimintamalleista.

"Se on monimutkainen asia. [Riskejä] tuodaan osittain [esille], osittain ei tuoda. Siis tää vanha perinne, et syyllinen etsitään ja se haukutaan ja sit jatketaan toimintaa niin kun ennenkin, niin sitä on vielä, vaikka kukaan ei sitä haluaisi tunnustaa, koska se on hävettävä ja kauhea, inhottava asia, ja uskon, että joka saakelin isossa organisaatiossa sitä on, tunnusti sitä tai ei." (T2)

Varmistamalla tarkoituksenmukaiset viestintäkanavat voidaan tukea kriiseistä oppimista. Helposti saatava ja ymmärrettävässä muodossa esitetty tieto on yksi kriiseistä oppimisen avaintekijöitä, muuten tieto ei pääse jalostumaan toiminnaksi. On tärkeää, missä ja miten turvallisuusasioista kerrotaan. Asiat pitää saattaa työntekijöiden tietoon muutoinkin kuin raskaina, intranetiin tallennettuina turvallisuusohjeistuksina. Kriiseistä oppimista voidaan kehittää esimerkiksi tekemällä turvallisuusasioista helposti lähestyttäviä videoita, uutisia ja tiivistelmiä.

Kriiseistä oppimista on mahdollista tukea jakamalla tietoa ja kokemuksia niin sairaaloiden sisällä kuin niiden välillä. Eri alojen asiantuntijoiden keskinäinen vuorovaikutus ja tiedon vaihdanta on tärkeää, ja säännöllisillä tapaamisilla voidaan parhaimmillaan vähentää päällekkäistä työtä ja kehittää keskinäistä toimintaa. Samalla asiantuntijat saavat tilaisuuden oppia toistensa tietämyksestä ja kokemuksista. 


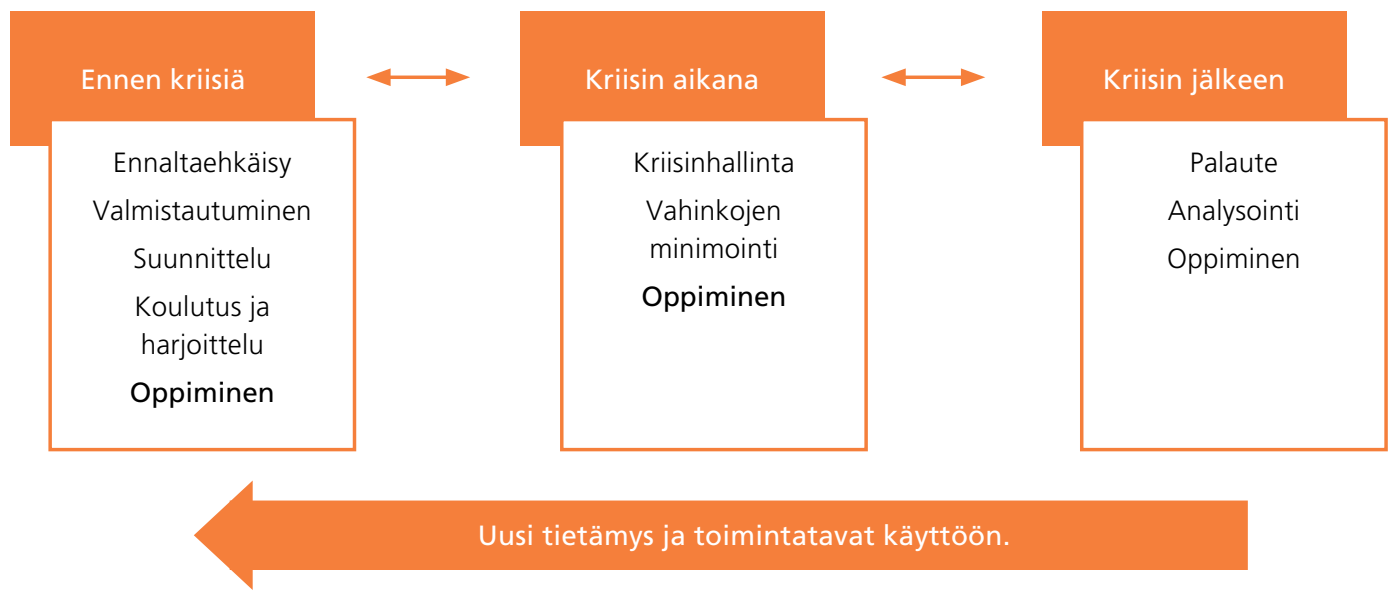

Kuvio 2. Muutosehdotus kolmivaiheiseen kriisisykliin: oppiminen on huomioitava myös ennen kriisiä ja kriisin aikana.

"Yritetään oppia myös muiden kriiseistä. Et se, että ottaa ite vaan turpaan ja oppii niistä, mut pitäis vähän kattoo, et miten naapurilla tapahtuu ja näin ja miksi se ei meillä muka vois tapahtua sitten. [--.] Nää ilmiöt kattoo harvoin alueiden rajoja ja organisaation rajoja." (T2)

Suuressa organisaatiossa on mahdotonta, että jostain tietystä turvallisuuden tai sisäisen kriisiviestinnän osa-alueesta vastaava henkilö voi itse kertoa asioista kasvotusten kaikille työntekijöille. Myöskään pelkkä tiedotus vaikkapa intranetissä ei riitä. Sairaaloissa onkin koettu hyväksi tavaksi kouluttaa turvallisuusyhteyshenkilöitä ja kasvattaa heistä turvallisuuslähettiläitä omiin yksiköihinsä tiedon ja kokemusten jakamiseksi. Toinen konkreettinen tiedon ja kokemusten jakamistapa ovat turvallisuuskävelyt: eri ammattialojen edustajat vierailevat yksiköissä ja käyvät yhdessä läpi turvallisuutta kohta kohdalta. Samalla he voivat konsultoida toisiaan ja pohtia yhdessä, miten turvallisuusasioita voidaan tuoda yhä paremmin esille.

\section{OPPIMINEN OSANA KRIISISYKLIÄ}

Tutkimuksemme perusteella kriiseistä oppimista voidaan tukea sairaaloissa painottamalla kriiseistä selviämisen sijaan ennaltaehkäiseviä toimia ja oppimista kriisin jokaisessa vaiheessa. Oppiminen sisällytetään kriisimalleissa usein vasta kriisin jälkeiseen vaihee- seen, vaikka mahdollisuus oppimiseen on läsnä koko ajan: niin ennen kriisiä, kriisin aikana kuin sen jälkeen (Veil 2011). Tutkimuksemme pohjalta näyttää tärkeältä, että oppiminen huomioidaan kaikissa kriisin vaiheissa. Kriisiviestinnän kirjallisuudesta tuttuun kolmivaiheiseen kriisimalliin (ks. esim. Frandsen \& Johansen 2011,355; Veil 2011, 117-121) onkin tarpeen lisätä oppiminen ennen kriisiä ja kriisin aikana (kuvio 2).

Oppia voidaan muutenkin kuin menneisyyteen katsomalla. Ennen kriisiä oppiminen tarkoittaa esimerkiksi toimintaympäristön kriittistä tarkastelua, riskien kartoittamista, heikkojenkin varoitussignaalien tunnistamista, omista ja muiden hyvistä ja huonoista kokemuksista oppimista sekä toiminnan muuttamista niin, että parhaimmassa tapauksessa kriisiä ei pääse lainkaan syntymään (Coombs 2010; Reynolds \& Seeger 2005; Veil 2011). Tämä edellyttää ajattelun suuntaamista kriisejä ennaltaehkäisevään toimintaan, avoimuutta ja prosessien kriittistä tarkastelua.

Kriisi vaatii organisaatiolta huomiota ja haastaa sen muuttamaan toimimattomia ajatus- ja toimintamallejaan. Kriisin aikana oppiminen on toiminnan korjaamista itse kriisin aikana siten, että kriisin negatiiviset seuraukset minimoidaan (Veil 2011). Oppiminen ei siis edellytä kriisin päättymistä, eikä oman toiminnan reflektointia ja kriisin analysointia tarvitse lykätä kriisin jälkeiseen aikaan. Koska monet kriisit, 
kuten pandemiat, ovat pitkäkestoisia, ne tarjoavat sairaaloille monenlaisia oppimismahdollisuuksia.

Kriisin jälkeen oppiminen tarkoittaa tapahtumien ja oman toiminnan analysointia ja arviointia jälkikäteen sekä ongelmien korjaamista ja toiminnan kehittämistä siten, ettei vastaava kriisi pääse enää uudelleen syntymään (Coombs 2007; Frandsen \& Johansen 2011; Veil 2011).

Koska oppiminen on mahdollista ennen kriisejä, kriisien aikana ja kriisien jälkeen, vastaisuudessa voitaisiin erottaa kriisejä varten oppiminen, kriiseissä oppiminen ja kriiseistä oppiminen. Mikään kokemus ei takaa oppimista, joten tarvitaan kokemuksien reflektointia, ja oppimisessa on tärkeää huomioida niin toimintaa edeltävä (Marsick ym. 2009, 59) kuin toiminnan aikainen ja toiminnan jälkeinen reflektio (Schön 1983, 49-69).

\section{LOPUKSI JA UUDEN ALUKSI}

Laadullisen tutkimuksen ideana on löytää aineiston avulla jotakin uutta ja ennen havaitsematonta (Ruusuvuori ym. 2010, 16). Yhdistämme kriisiviestinnän, turvallisuuskulttuurin ja kriiseistä oppimisen samaan tutkimukseen, mikä on harvinaista ja osoittautui tämän tutkimuksen vahvuudeksi. Tutkimuksemme antaa tuoreen näkökulman yliopistollisten sairaaloiden turvallisuuskulttuurin kehittämiseen ja kriiseistä oppimisen tukemiseen.

Tulosten mukaan turvallisuuskulttuuria voidaan kehittää sairaaloissa synnyttämällä jaettua ymmärrystä turvallisuudesta, huomioimalla turvallisuusnäkökulmat kaikessa tekemisessä, kehittämällä ohjeistuksia, tukemalla yhteistyötä ja ehkäisemällä pirstaloitumista, osallistamalla työntekijöitä sekä kehittämällä johtamista. Olennaista on pyrkiä tasapainoon rutiinien ja joustavuuden, korjaamisen ja ennakoinnin, hierarkian ja vastuunjaon, suunnitelmien ja käytännön sekä sulkeutuneisuuden ja avoimuuden jännitteiden välillä. Tutkimuksemme lisäsi ymmärrystä turvallisuuskulttuurin kehittämisestä sairaaloissa etenkin sairaaloiden turvallisuuskulttuuria haastavien jännitteiden osalta.

Kriiseistä oppimista voidaan tukea tarjoamalla koulutusta, lisäämällä avoimuutta, varmistamalla tarkoituksenmukaiset viestintäkanavat sekä jakamalla tietoa ja kokemuksia. Tulostemme pohjalta esitämme muutosta kolmivaiheisen kriisisyklin perinteisiin painotuksiin: oppiminen sisällytetään kriisimalleissa usein vasta kriisin jälkeiseen vaiheeseen (ks. esim. Frandsen \& Johansen 2011; Veil 2011), mutta tutkimuksemme mukaan oppiminen on tärkeä elementti niin ennen kriisejä, kriisien aikana kuin kriisien jälkeen. Sairaaloissa onkin tärkeää painottaa kriiseistä selviämisen sijaan ennaltaehkäiseviä toimia ja oppimista kriisin jokaisessa vaiheessa.

Lähestyimme tutkimusaihettamme erityisesti sairaaloiden sisäisen kriisiviestinnän näkökulmasta. Yliopistollisissa sairaaloissa työskentelee tuhansia henkilöitä, ja tutkimukseen osallistuneiden turvallisuus- ja viestintäpäälliköiden mukaan sairaaloiden sisäinen kriisiviestintä on keskeisessä asemassa niin turvallisuuskulttuurin kehittämisessä kuin kriiseistä oppimisen tukemisessa. Sairaaloiden sisäisessä kriisiviestinnässä on kuitenkin vielä kehittämisen varaa.

Viestintä ei ole vain viestintäyksikön tai viestinnän ammattilaisten työtä vaan jokaisen työntekijän tehtävä (Laajalahti \& Pennanen 2019, 31). Vastaavasti organisaatioiden sisäinen kriisiviestintä kuuluu kaikille (Frandsen \& Johansen 2011, 352; Strandberg \& Vigsø 2016, 89). Sairaaloiden turvallisuuskulttuurin kehittämiseksi on tärkeää tuoda eri työtehtävissä toimivia työntekijöitä ja johtajia yhteen keskustelemaan ja luomaan yhdessä jaettua ymmärrystä turvallisuudesta (O’Donovan ym. 2019, 871; Nordin ym. 2020, 320). Sisäisen kriisiviestinnän kehittämiseen tulisi osallistaa koko sairaaloiden henkilökunta työntekijöistä johtajiin. Sisäinen kriisiviestintä on tärkeää ymmärtää kaikkien yhteiseksi ja kaikkien työhön erottamattomasti kuuluvaksi prosessiksi. Turvallisuus tehdään yhdessä.

Lähestyimme tutkimusaihetta haastateltavien kokemana ja kuvaamana, ja erilaisten syy-seuraussuhteiden sekä asioiden yleisyyden selvittämiseksi tarvittaisiin jatkotutkimusta. Aihetta voidaan tarkastella vielä systemaattisemmin esimerkiksi tutkimalla ohjeistuksien määriä, sisältöjä ja käyttölukuja sekä turvallisuus- ja viestintäpäälliköiden yhteistyötä käytännössä. Myös erilaisten vertailujen, kuten sairaaloiden tai kulttuurien välisten erojen ja yhtäläisyyksien, 
KinnNostavaA EI OLE VAIN

SE, MITEN J ̈̈NNITTEISIIN

VASTATAAN VAAN MYÖS

SE, MITEN NIIHIN OPITAAN

VASTAAMAAN KUTEN NIIHIN

VASTATAAN.

selvittämiseksi tarvitaan toisenlaisin menetelmin toteutettua jatkotutkimusta (ks. lisäksi Lee \& Quinn 2020, 220).

Vaikka turvallisuus- ja viestintäpäälliköiden mukaan sairaaloiden sisäinen kriisiviestintä on tärkeää turvallisuuskulttuurin kehittämisessä ja kriiseistä oppimisen tukemisessa, ei onnistuneinkaan kriisiviestintä yksinään riitä. Turvallisuuskulttuurin kehittäminen ja kriiseistä oppimisen tukeminen ovat moniulotteisia ilmiöitä, joiden onnistumiseen vaikuttavia tekijöitä on tarpeen tutkia lisää niin yksilö-, ryhmä- kuin organisaatiotasolla. Yhä tarkempaa huomiota tulee kiinnittää myös johtamiseen. Aiempien tutkimusten mukaan johtajien tulee omaksua johtamisstrategioita, jotka tukevat työntekijöiden psykologista turvallisuutta ja luovat sairaaloihin reilua turvallisuuskulttuuria (O'Donovan ym. 2019, 871).

On kiinnostavaa tarkentaa tutkimusta koskemaan esimerkiksi sairaaloiden työntekijöiden ja johtajien turvallisuuteen liittämiä arvostuksia ja motivaatiotekijöitä, oppimiseen ja sen tukemiseen liittyviä oppimiskäsityksiä sekä esimerkiksi uravaiheeseen, osaamiseen ja tehtävänkuvaan liittyviä yksilöllisiä eroja ja yhtäläisyyksiä. Kokonaisten tiimien tai yksiköiden vuorovaikutusta ja yhteisiä merkityksenantoja tutkimalla voidaan sen sijaan syventää ymmärrystä esimerkiksi siitä, miten riskeistä ja heikoista signaaleista neuvotellaan ja turvallisuudesta synnytetään jaettua ymmärrystä. Sairaaloiden turvallisuuskulttuuria haastavien jännitteiden osalta oppiminen on mielenkiintoinen jatkotutkimuskohde, sillä kiinnostavaa ei ole vain se, miten jännitteisiin vastataan vaan myös se, miten niihin opitaan vastaamaan niin kuin niihin vastataan (Laajalahti 2014, 189).

Viestinnän ammattilaiset kutsutaan usein mukaan "jälkipyykkiin" vasta sitten, kun kriisi on jo ohi (Heide \& Simonsson 2014). Turvallisuuskulttuurin kehittäminen ja kriiseistä oppimisen tukeminen edellyttävät kuitenkin eri alojen asiantuntijoiden osaamista, osallistamista ja yhteistyötä jo hyvissä ajoin ennen kriisiä. Turvallisuuskulttuurin kehittämisessä ja kriiseistä oppimisen tukemisessa tarvitaan pitkäjänteistä yhteistyötä turvallisuuden ja kriisiviestinnän asiantuntijoiden lisäksi organisaatioiden oppimiseen erikoistuneiden henkilöiden kanssa. Aikuiskasvatuksen näkökulmia tarvitaan, koska jatkuva oppiminen on turvallisuuskulttuurin kehittämisen ja kriiseistä oppimisen tukemisen perusta.

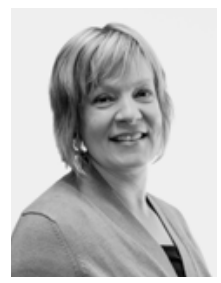

\section{ERIKKA MANNILA}

FM, tiedotuspäällikkö

Maavoimat

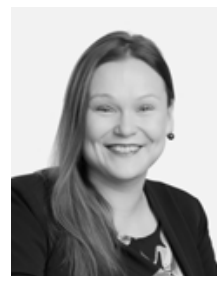

ANNE LAAJALAHTI

$\mathrm{FT}$, viestintätieteiden dosentti Vaasan yliopisto

koulutus- ja kehittämisjohtaja Infor / Management Institute of Finland MIF Oy

(D) https://orcid.org/0000-00024321-8275

Artikkeli perustuu FM Erikka Mannilan Jyväskylän yliopistoon tekemään yhteisöviestinnän maisterintutkielmaan "Kohti turvallisuuden kulttuuria: kuinka viestinnän keinoin voi kehittää organisaation turvallisuutta?" (2017). Työtä ohjasi FT, koulutus- ja kehittämisjohtaja Anne Laajalahti. 
Adkins, G. L. (2010). Organizational networks in disaster response: An examination of the US government network's efforts in Hurricane Katrina. Teoksessa W. T. Coombs \& S. J. Holladay (toim.) The Handbook of Crisis Communication. Chichester: Wiley-Blackwell, 93-114. https://doi. org/10.1002/9781444314885.ch4

Baxter, L. A. \& Montgomery, B. M. (1996). Relating: Dialogues and Dialectics. New York: Guilford.

Boano, C. \& Lund, R. (2011). Disasters, crisis and communication: A literature review. Teoksessa M. Vos, R. Lund, H. Harro-Loit \& Z. Reich (toim.) Developing a Crisis Communication Scorecard. Jyväskylän yliopisto. Jyväskylä Studies in Humanities 152, 49-154.

Chess, C. (2001). Organizational theory and the stages of risk communication. Risk Analysis 21(1), 179-188. https://doi.org/10.1111/0272-4332.211100

Collin, K. (2002). Development engineers' conceptions of learning at work. Studies in Continuing Education 24(2), 133-152. https://doi. org/10.1080/0158037022000020956

Coombs, W. T. (2007). Ongoing Crisis Communication: Planning, Managing, and Responding. 2. painos. Thousand Oaks: Sage.

Coombs, W. T. (2010). Parameters for crisis communication. Teoksessa W. T. Coombs \& S. J. Holladay (toim.) The Handbook of Crisis Communication. Chichester: Wiley-Blackwell, 17-53. https://doi.org/10.1002/9781444314885.ch1

Eskola, S. (2008). Turvallisuus käsitteenä. Helsinki: Maanpuolustuskorkeakoulu. https://www.doria. fi/bitstream/handle/10024/74107/StratL3_10. pdf? sequence $=1$ \&isAllowed=y (2.7.2019).

Falkheimer, J. \& Heide, M. (2010). Crisis communicators in change: From plans to improvisations. Teoksessa T. Coombs \& S. J. Holladay (toim.) The Handbook of Crisis Communication. Chichester: Wiley-Blackwell, 511-526. https://doi.org/10.1002/9781444314885. ch25

Frandsen, F. \& Johansen, W. (2011). The study of internal crisis communication: Towards an integrative framework. Corporate Communications: An International Journal 16(4), 347-361. https://doi. org/10.1108/13563281111186977

Gluyas, H. (2015). Effective communication and teamwork promotes patient safety. Nursing Standard 29(49), 50-57. https://doi.org/10.7748/ns.29.49.50.e10042

Heide, M. \& Simonsson, C. (2014). Developing internal crisis communication: New roles and practices of communication professionals. Corporate Communications: An International Journal 19(2), 128-146. https://doi.org/10.1108/CCIJ-09-20120063
Heide, M. \& Simonsson, C. (2015). Struggling with internal crisis communication: A balancing act between paradoxical tensions. Public Relations Inquiry 4(2), 223-255. https://doi. org/10.1177/2046147X15570108

Hirsjärvi, S. \& Hurme, H. (2008). Tutkimushaastattelu: Teemahaastattelun teoria ja käytäntö. Helsinki: Gaudeamus.

Keyton, J. (2011). Communication and Organizational Culture: A Key to Understanding Work Experiences. 2. painos. Thousand Oaks: Sage.

Kinnunen, M. (2010). Virheistä oppimisen esteet ja mahdollistajat organisaatiossa. Vaasan yliopisto. Acta Wasaensia No 230.

Kofman, F. \& Senge, P. M. (1993). Communities of commitment: The heart of learning organizations. Organizational Dynamics 22(2), 4-23. http://dx.doi. org/10.1016/0090-2616(93)90050-B

Kokonaisturvallisuuden sanasto (2017). 2. painos. Helsinki: Sanastokeskus TSK ry. https://turvallisuuskomitea.fi/ materiaalit/kokonaisturvallisuuden-sanasto (2.7.2019).

Laajalahti, A. (2014). Vuorovaikutusosaaminen ja sen kehittyminen tutkijoiden työssä. Jyväskylän yliopisto. Jyväskylä Studies in Humanities 225. http://urn.fi/ URN:ISBN:978-951-39-5618-9

Laajalahti, A. (2016). Kriisiviestinnästä kriisivuorovaikutukseen: Puheviestinnän näkökulmia kriiseissä ja kriiseistä viestimiseen. Teoksessa M. Siitonen, M. Lahti, J. Koponen \& R. Vanhatalo (toim.) Prologi: Puheviestinnän vuosikirja 2016. Jyväskylä: Prologos ry, 76-82. https:// doi.org/10.33352/prlg.95914

Laajalahti, A. \& Pennanen, E. (2019). Työpaikasta osallistuvaksi työyhteisöksi. Teoksessa V. Luoma-aho \& K. Pekkala (toim.) Osallistava viestintä. Helsinki: ProCom ry, 26-38.

Larsson, L. (2010). Crisis and learning. Teoksessa T. Coombs \& S. J. Holladay (toim.) The Handbook of Crisis Communication. Chichester: Wiley-Blackwell, 713-718. https://doi.org/10.1002/9781444314885.ch38

Lee, S. E., Scott, L. D., Dahinten, V. S., Vincent, C., Lopez, K. D. \& Park, C. G. (2019). Safety culture, patient safety, and quality of care outcomes: A literature review. Western Journal of Nursing Research 41(2), 279-304. https://doi.org/10.1177/0193945917747416

Lee, S. E. \& Quinn, B. (2020). Safety culture and patient safety outcomes in East Asia: A literature review. Western Journal of Nursing Research 42(3), 220-230. https://doi.org/10.1177/0193945917747416

Leonard, M., Graham, S. \& Bonacum, D. (2004). The human factor: The critical importance of effective teamwork and communication in providing safe care. Quality and Safety in Health Care 13(1), 85-90. http:// dx.doi.org/10.1136/qshc.2004.010033 
Marsick, V. J. \& Watkins, K. E. (2003). Demonstrating the value of an organization's learning culture: The dimensions of the learning organization questionnaire. Advances in Developing Human Resources 5(2), 132 151. https://doi.org/10.1177/1523422303005002002

Marsick, V. J., Watkins, K. E., Callahan, M. W. \& Volpe, M. (2009). Informal and incidental learning in the workplace. Teoksessa M. C. Smith \& N. DeFrates-Densch (toim.) Handbook of Research on Adult Learning and Development. New York: Routledge, 570-600.

Mazzei, A. \& Ravazzani, S. (2011). Manageremployee communication during a crisis: The missing link. Corporate Communications: An International Journal 16(3), 243-254. https://doi. org/10.1108/13563281111156899

Mazzei, A. \& Ravazzani S. (2015). Internal crisis communication strategies to protect trust relationships: A study of Italian companies. International Journal of Business Communication 52(3), 319-337. https://doi. org/10.1177/2329488414525447

Morello, R. T., Lowthian, J. A., Barker, A. L., McGinnes, R., Dunt, D. \& Brand, C. (2013). Strategies for improving patient safety culture in hospitals: A systematic review. BMJ Quality \& Safety 22(1), 1-8. http://dx.doi. org/10.1136/bmjqs-2011-000582

Nordin, A., Nordström, G., Wilde-Larsson, B., Hallberg, A. \& Theander, K. (2020). Patient safety culture change over time: Health care staffs' perceptions. Open Journal of Nursing 10, 320-339. https://doi. org/10.4236/ojn.2020.103022

O’Donovan, R., Ward, M., De Brún, A. \& McAuliffe, E. (2019). Safety culture in health care teams: A narrative review of the literature. Journal of Nursing Management 27(5), 871-883. https://doi. org/10.1111/jonm. 12740

Oikeusministeriö (1989/1062). Erikoissairaanhoitolaki. http://www.finlex.fi/fi/laki/ajantasa/1989/19891062 (6.7.2019).

Oikeusministeriö (1992/785). Laki potilaan asemasta ja oikeuksista. http://www.finlex.fi/fi/laki/ ajantasa/1992/19920785 (6.7.2019).

Oikeusministeriö (2018/1050). Tietosuojalaki. http://www. finlex.fi/fi/laki/ajantasa/2018/20181050 (6.7.2019).

Pandit, B., Albert, A., Patil, Y. \& Al-Bayati, A. J. (2019). Fostering safety communication among construction workers: Role of safety climate and crew-level cohesion. International Journal of Environmental Research and Public Health 16(1), 1-16. https://doi. org/10.3390/ijerph16010071

Pietikäinen, E., Oedewald, P., Haavisto, M.-L., Reiman, T., Ruuhilehto, K. \& Heikkilä, J. (2010). Pyrkivätkö turvallisuuskriittiset organisaatiot oppimaan kokemuksistaan? Kokemustiedon käsittelyä ohjaavat oletukset ydinvoimateollisuudessa ja terveydenhuollossa. Työelämän tutkimus 8(3), 279-290.
Reiman, T. \& Oedewald, P. (2008). Turvallisuuskriittiset organisaatiot - onnettomuudet, kulttuuri ja johtaminen. Helsinki: Edita.

Reynolds, B. \& Seeger, M. W. (2005). Crisis and emergency risk communication as an integrative model. Journal of Health Communication 10(1), 4355. https://doi.org/10.1080/10810730590904571

Ruusuvuori, J., Nikander, P. \& Hyvärinen, M. (2010). Haastattelun analyysin vaiheet. Teoksessa J. Ruusuvuori, P. Nikander \& M. Hyvärinen (toim.) Haastattelun analyysi. Tampere: Vastapaino, 9-38.

Schein, E. (1984). Coming to a new awareness of organizational culture. Sloan Management Review 25(2), 3-16.

Schermuly, C. C., Draheim, M., Glasberg, R., Stantchev, V., Tamm, G., Hartmann, M. \& Hessel, F. (2015). Human resource crises in German hospitals - An explorative study. Human Resources for Health 13(40), 1-10. https://doi.org/10.1186/s12960-015-0032-4

Schwandt, T. A. (2007). The Sage Dictionary of Qualitative Inquiry. 3. painos. Thousand Oaks: Sage. https://dx.doi.org/10.4135/9781412986281

Schön, D. A. (1983). The Reflective Practitioner: How Professionals Think in Action. New York: Basic Books.

Stavrianopoulos, T. (2012). The development of patient safety culture. Health Science Journal 6(2), 201-211.

Seeger, M. W., Sellnow, T. L. \& Ulmer, R. R. (2003). Communication and Organizational Crisis. Westport: Praeger.

Sosiaali- ja terveysministeriö (2019). Sairaalat ja erikoissairaanhoito. http://www.stm.fi/sairaalaterikoissairaanhoito (6.7.2019).

Strandberg, J. M. \& Vigsø, O. (2016). Internal crisis communication: An employee perspective on narrative, culture, and sensemaking. Corporate Communications: An International Journal 21(1), 89-102. https://doi.org/10.1108/CCIJ-11-2014-0083

Ulmer, R. R., Sellnow, T. L. \& Seeger, M. W. (2015). Effective Crisis Communication: Moving from Crisis to Opportunity. 3. painos. Thousand Oaks: Sage.

Veil, S. R. (2011). Mindful learning in crisis management. International Journal of Business Communication 48(2), 116-147. https://doi. org/10.1177/0021943610382294

Vos, M. (2017). Communication in Turbulent Times: Exploring Issue Arenas and Crisis Communication to Enhance Organisational Resilience. Jyväskylä: Jyväskylän yliopisto.

Wang, J., Hutchins, H. M. \& Garavan, T. N. (2009). Exploring the strategic role of human resource development in organizational crisis management. Human Resource Development Review 8(1), 22-53. https://doi.org/10.1177/1534484308330018 